\title{
Seasonal variability and descent of mid-latitude sporadic E layers at Arecibo
}

\author{
N. Christakis ${ }^{1}$, C. Haldoupis ${ }^{2}$, Q. Zhou ${ }^{3}$, and C. Meek ${ }^{4}$ \\ ${ }^{1}$ Department of Applied Mathematics, University of Crete, Heraklion, Greece \\ ${ }^{2}$ Physics Department, University of Crete, Heraklion, Greece \\ ${ }^{3}$ Department of Electrical and Computer Engineering, Miami University, Oxford, OH, USA \\ ${ }^{4}$ Institute of Space and Atmospheric Studies, University of Saskatchewan, Canada
}

Received: 15 October 2008 - Revised: 26 January 2009 - Accepted: 30 January 2009 - Published: 2 March 2009

\begin{abstract}
Sporadic E layers $\left(E_{s}\right)$ follow regular daily patterns in variability and altitude descent, which are determined primarily by the vertical tidal wind shears in the lower thermosphere. In the present study a large set of sporadic E layer incoherent scatter radar (ISR) measurements are analyzed. These were made at Arecibo (Geog. Lat. $\sim 18^{\circ} \mathrm{N}$; Magnetic Dip $\sim 50^{\circ}$ ) over many years with ISR runs lasting from several hours to several days, covering evenly all seasons. A new methodology is applied, in which both weak and strong layers are clearly traced by using the vertical electron density gradient as a function of altitude and time. Taking a time base equal to the 24-h local day, statistics were obtained on the seasonal behavior of the diurnal and semidiurnal tidal variability and altitude descent patterns of sporadic $\mathrm{E}$ at Arecibo. The diurnal tide, most likely the $\mathrm{S}(1,1)$ tide with a vertical wavelength around $25 \mathrm{~km}$, controls fully the formation and descent of the metallic $E_{s}$ layers at low altitudes below $110 \mathrm{~km}$. At higher altitudes, there are two prevailing layers formed presumably by vertical wind shears associated mainly with semidiurnal tides. These include: 1) a daytime layer starting at $\sim 130 \mathrm{~km}$ around midday and descending down to $105 \mathrm{~km}$ by local midnight, and 2) a less frequent and weaker nighttime layer which starts prior to midnight at $\sim 130 \mathrm{~km}$, descending downwards at somewhat faster rate to reach $110 \mathrm{~km}$ by sunrise. The diurnal and semidiurnal-like pattern prevails, with some differences, in all seasons. The differences in occurrence, strength and descending speeds between the daytime and nighttime upper layers are not well understood from the present data alone and require further study.
\end{abstract}

Correspondence to: N. Christakis (nchristakis@tem.uoc.gr)
Keywords. Ionosphere (Ionosphere-atmosphere interactions; Mid-latitude ionosphere) - Radio science (Ionospheric physics)

\section{Introduction}

Incoherent scatter radar (ISR) and ionosonde studies show that mid- and low-latitude sporadic E is not as "sporadic" as its name implies but a regularly occurring phenomenon at low mid-latitudes. There is a repeatability in $E_{s}$ layer occurrence and altitude descent that is attributed to the global system of the tidal winds in the lower thermosphere. As shown by Mathews (1998) in his review paper, the Arecibo ISR observations revealed a fundamental role played by the diurnal and semidiurnal tides in the formation and descent of sporadic $\mathrm{E}$ layers, which often are also referred to as "tidal ion layers" (TILs). The 12- and 24-h tidal effects on $E_{s}$ formation have been recognized also in ionosonde observations at midlatitudes (see e.g. Haldoupis et al., 2006, and more references therein). The connection between $E_{s}$ and tides is not surprising given that the dominant winds in the E-region are the solar tides (Chapman and Lindzen, 1970). These govern the variability and descent of sporadic $\mathrm{E}$ through their vertical wind shears, which also move downward following the tidal phase speed propagation. All this is in line with the windshear theory and numerical models (see e.g. Whitehead, 1989; Carter and Forbes, 1999), which predict metallic ion layer formation at vertical wind shear ion-convergence nodes.

Although there exists an understanding on the tidal variability and descent of sporadic E layers, there are still unresolved complexities in this process, which require further study. For example, a point of uncertainty relates to the role

Published by Copernicus Publications on behalf of the European Geosciences Union. 
Number of days per calendar month

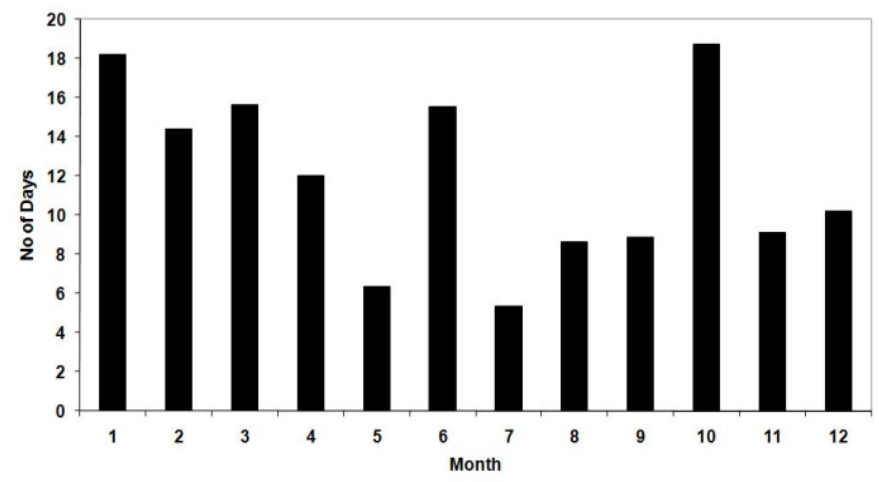

(a)

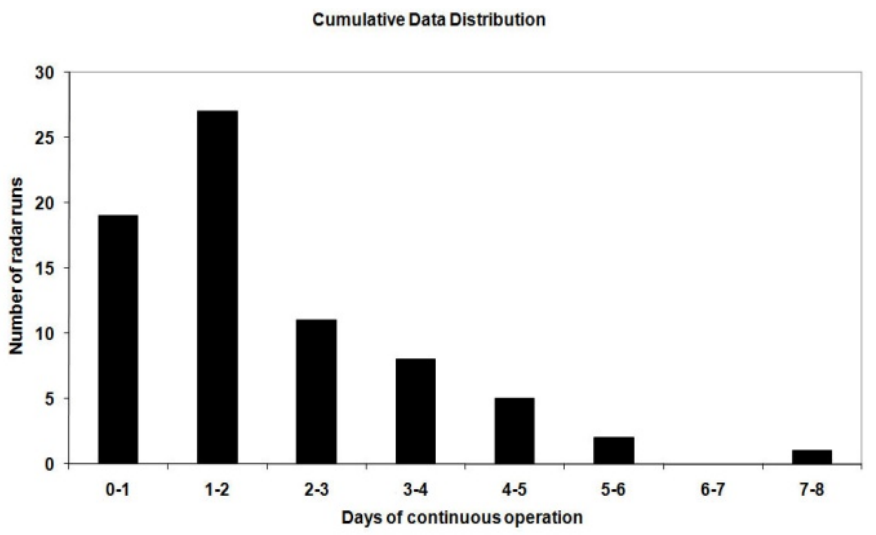

(b)

Fig. 1. The Arecibo ISR electron density profile measurements used in the present study: (a) distribution of observation days per month per calendar year over a period of 14 years, and (b) distribution of ISR continuous operation intervals in days.

and importance of the semidiurnal tides on the formation and descent of $E_{s}$. Questions also exist with respect to the confluence of the various tidal modes, as well as their overall dominant features, which if they can be defined then could be implemented in large-scale atmosphere-ionosphere models. Moreover, there are questions about the tidal effects on basic $E_{s}$ properties, such as the diurnal and seasonal variability of the layers, which are still not well understood.

The purpose of the present work is to provide more insight into the nature of sporadic $\mathrm{E}$ tidal variability and layer descent. To achieve this objective, we use an extended set of incoherent scatter radar (ISR) electron density observations made at Arecibo over many years with radar runs lasting from several hours to several days with a reasonably good seasonal coverage. Furthermore, in the present work a new method to analyze the sporadic E layer ISR radar measurements is applied, in which, instead of using the measured electron density as a function of altitude and time to trace the layers, we use the vertical electron density gradient $d N_{e} / d z$. The logarithm of this quantity turns out to be a sensitive parameter in tracing the altitudinal layer structure and in identifying well both strong and weak layers in altitude as a function of time. Recent works using the Arecibo ISR to study $E_{S}$ ion layers, neutral metal layers in the lowest E-region, as well as the upper $E$ region intermediate descent layers include those by Zhou et al. (2005, 2008), Earle et al. (2000), Bishop et al. (2002) and Bishop and Earle (2003).

In the present paper we concentrate on the mean seasonal behavior of sporadic $\mathrm{E}$ in terms of its tidal variability. To our knowledge, this is the first statistical study on $E_{s}$ done by means of using ISR measurements. Also we infer from the data typical tidal wave parameters, especially with regards to the diurnal tide, which dominates thermospheric heights below $110 \mathrm{~km}$ at low latitudes, and use a simple model to exemplify the tidal effects on $E_{S}$ altitude descent versus local day time.

\section{Data and method of analysis}

The ISR at Arecibo (Geog. Lat. $\sim 18^{\circ} \mathrm{N}$; Geom. Lat. $\sim 30^{\circ} \mathrm{N}$ ) is the best instrument available to monitor the ionospheric structure with superb sensitivity and good range and time resolution. Among various ionospheric phenomena, the Arecibo radar is particularly suited for investigating the altitudinal structure and dynamics of narrow sporadic E layers. Contrary to previous Arecibo $E_{S}$ studies which were based on radar runs of a few days, statistical estimates are obtained here for the first time by using a large set of measurements. These comprise about 140 days of radar observations distributed over all seasons, made over a period of 14 years from 1986 to 2000 (for details on the radar operation mode see Zhou, 1998). In the present analysis, electron density profiles measured between 60 and $480 \mathrm{~km}$ with $600 \mathrm{~m}$ altitude resolution integrated over times of a few seconds are analyzed. The individual observational periods range from part of a day to 8 days. The histograms in Fig. 1 summarize the monthly observations distributed over a calendar year and the duration in days of continuous radar observations. As seen, the observing periods are distributed fairly evenly over the year, whereas the average continuous radar run duration is $\sim 2.3$ days.

Since the efforts here focus on studying the tidal variability of sporadic $\mathrm{E}$ in altitude and time and not their strength in terms of electron density, a novel method is introduced for analysis, which makes use of the electron density gradient $\log \left(d N_{e} / d z\right)$, instead of $\log N_{e}$ to produce height-timeintensity (HTI) displays (the term "intensity" here refers to the logarithm magnitude of the (positive) vertical electron 
(a)

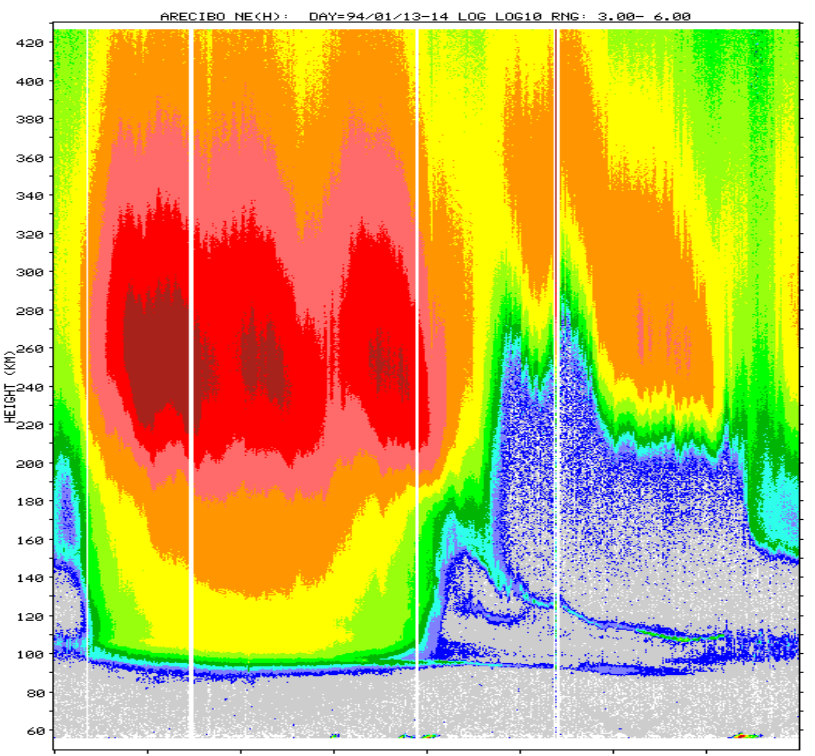

(b)

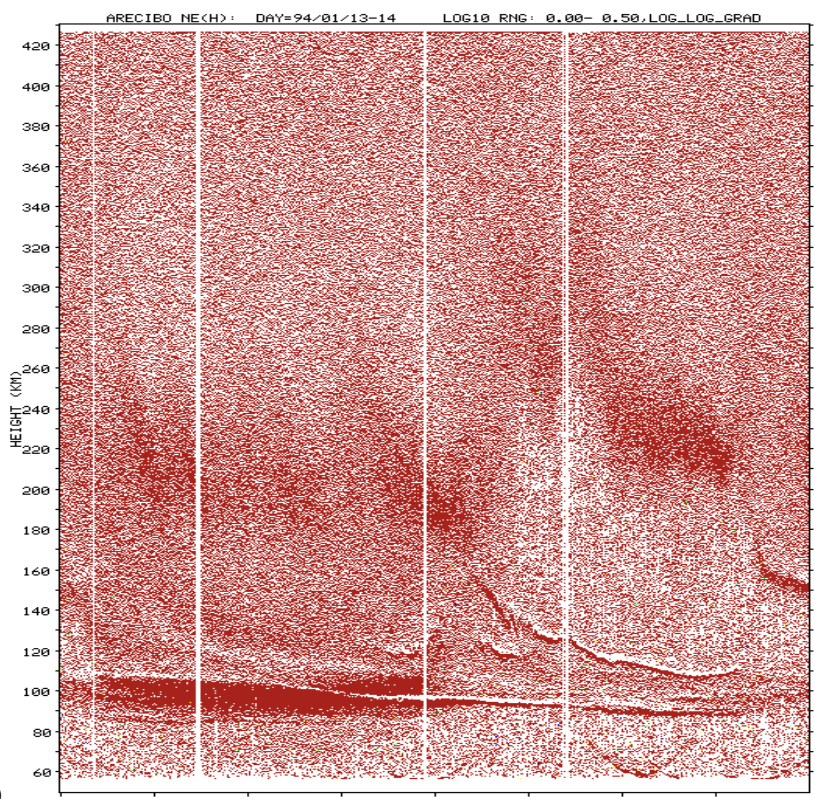

Fig. 2. Example of different presentation of the measured electron density profiles by the Arecibo ISR during a period of $24 \mathrm{~h}$ starting at 06:00 LT (ordinate axis). The left panel is the usual $\log N_{e}$ height-time-intensity (HTI) plot whereas in the right panel is the $\log \left(d N_{e} / d z\right)$ plot used for the purposes of the present study.

density gradient). The software developed for this purpose computes HTI plots within a range of heights versus one 24$\mathrm{h}$ local day, chosen with the purpose of investigating tidal effects on sporadic E. As inferred from Fig. 2, which shows HTI plots for $\log N_{e}$ and $\log \left(d N_{e} / d z\right)$ for a typical day of observation, the $\log \left(d N_{e} / d z\right)$ method detects the location of narrow sporadic E layers rather accurately, thus it is rather suitable for studying the layer tidal variability and descent with time.

Data from approximately 140 days over a period of 14 years have been gathered and analyzed. Examples of typical $\log \left(d N_{e} / d z\right)$ HTI plots are presented in Fig. 3 for two different periods of two consecutive days. The dominant features and complexity of the layering structures are well depicted. The available data were separated according to season and the traces were first classified in identifiable groups and then digitized manually with the aid of GetData-Graph Digitizer (Fedorov, 2008) software. Careful inspection of the entire number of the HTI plots led to identification of 3 main groups of layers, a diurnal trace at lower altitudes below $110 \mathrm{~km}$ and two upper layers, a daytime and a nighttime one. The traces of every available day (or fragment of day) were output as mean hourly samples over a 24-h day. The analysis included only those traces which could be clearly seen in the HTI plots for at least part of one hour and could be identified as part of an ongoing layer structure. For instance, at the top left panel of Fig. 3 the small trace at $120 \mathrm{~km}$ between $02: 00 \mathrm{~h}$ and 03:00 h local time (LT) was not considered, since it could not be clearly identified as part of a persisting layer. Next, the dominant traces were averaged for every one of the four seasons.

\section{Presentation of results}

The statistics of the main sporadic E layers with altitude and local time during a 24-h day period are summarized in the following 4 figures for the seasons of winter (Fig. 4), spring (Fig. 5), summer (Fig. 6) and fall (Fig. 7). Each figure has two parts: 1) the upper panel containing histograms of the hourly samples available for all the identified groups of layers present in the HTI plots, thus indicating the relative occurrence of each group, and 2) the lower panel showing the mean location of the corresponding layers plotted in altitude versus local time for the 24-h day period starting at 06:00 LT. The information in the two panels is color-coded for identification, whereas the error bars in the lower panel are the mean deviation from the mean, representing the variability in the layer's altitude location at a given local time.

In our understanding, the tides provide the convergent wind shears needed for the layers to form and build up, while tidal phase propagation downwards accounts for the layers' negative slope with time which, however, is also subject to ion-neutral collisional control that increases with decreasing altitude. Inspection of the results show a well defined behavior for all seasons characterized by certain discrete traces, all sloping negatively with time. They include a dominant diurnal trace seen at lower altitudes below $110 \mathrm{~km}$, which must 

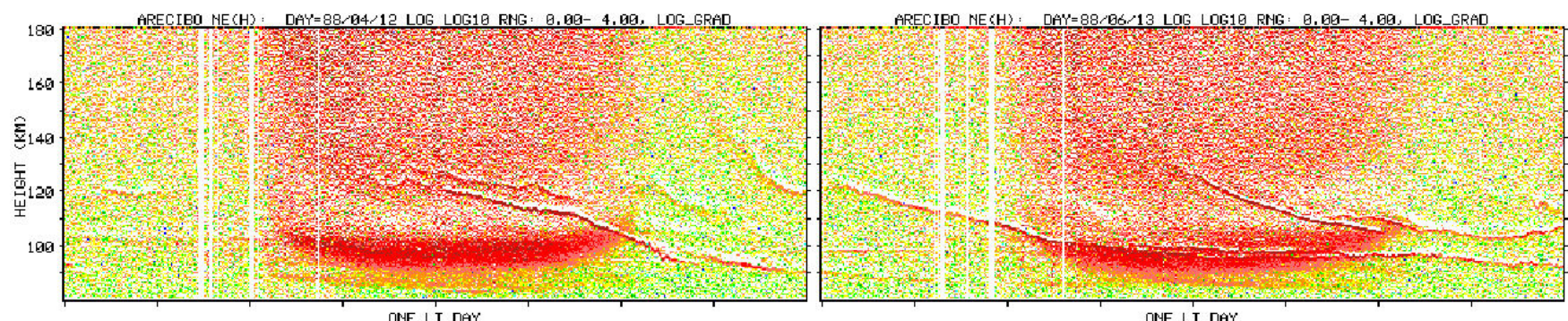

ONE LT DAY

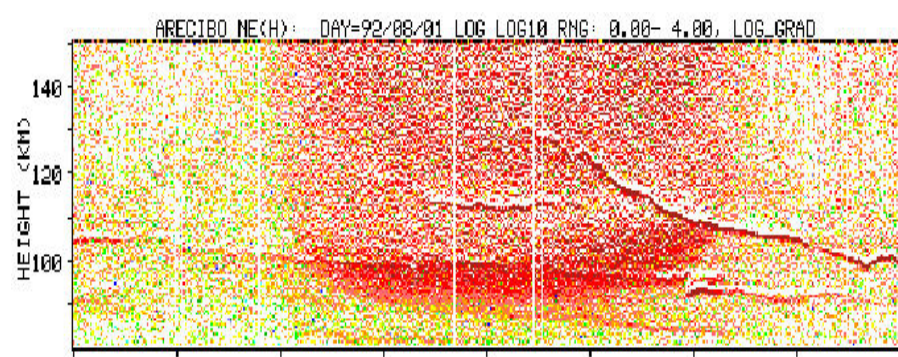

OME LT DAY

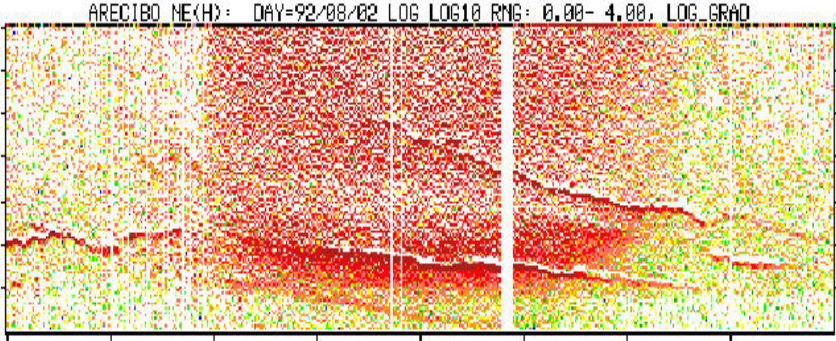

ONE LT DAY

Fig. 3. Typical $\log \left(d N_{e} / d z\right)$ HTI plots used in the present study for identifying the different $E_{s}$ layers prevailing in the Arecibo data. These traces were first grouped and then digitized, so they could be statistically analyzed for every season.

relate to the diurnal tide, and two upper altitude traces referring to a daytime and a nighttime descending layer, spaced about 10 to $12 \mathrm{~h}$ apart, apparently being controlled mainly by the semidiurnal tide.

The diurnal trace sets in at sunrise somewhat below $110 \mathrm{~km}$, while the semidiurnal-like ones prevailing at higher altitudes start at about $130 \mathrm{~km}$ a couple of hours prior to local noon and midnight, respectively. Downward speeds are clearly larger for the semi-diurnally forced layers, which gradually move down and merge with, or taken over by, the slowly descending diurnal layer below. The dominant feature in the data is the diurnal tidal trace which descends from about $106 \mathrm{~km}$ down to $\sim 90 \mathrm{~km}$ over a period of $24 \mathrm{~h}$. During summer however, a weaker upper diurnal-like trace is also present at times, starting at about 120 to $125 \mathrm{~km}$ to descend with approximately the same speed as the dominant diurnal trace below. This might be regarded as evidence that the diurnal tide starts higher up in the summer than in other seasons.

As seen from the histograms in Figs. 4 to 7, the semidiurnal-like upper traces are less frequent than the prevailing diurnal trace at lower altitudes. In addition, the daytime layer is better defined and more frequent than the nighttime one. The evidence shows that both connect higher up with the so called intermediate descending layers (IDL) which are broader and weaker but commonly present in the Arecibo $N_{e}$ profiles (see e.g. Mathews, 1998, and references therein). On the average, the daytime layer appears a couple of hours prior to midday at about $130 \mathrm{~km}$ and moves down to $\sim 105 \mathrm{~km}$ by midnight with decreasing speeds from $\sim 3.5$ to $2.5 \mathrm{~km} / \mathrm{h}$. The less frequent and intermittent night- time layer appears at $\sim 130 \mathrm{~km}$ near 22:00 LT, moving down to $\sim 110 \mathrm{~km}$ by $06: 00 \mathrm{LT}$ with average speeds ranging from $\sim 4.0$ to $3.0 \mathrm{~km} / \mathrm{h}$. Finally, the trace altitudinal variability, signified by the error bars in the lower panels of Figs. 4 to 7 , can be attributed to various reasons. A likely one is the modulation of tides by planetary waves in the mesosphere. This was proposed by Pancheva et al. (2003) as the mechanism behind the PW-like variability of sporadic E layers. Another possibility is the confluence in forming a layer of more than one tidal modes at a given time and/or contributions from gravity waves.

Figure 8 offers a visual comparison of the statistical results for all four seasons by superimposing the observed mean traces for the lower altitude diurnal ion layer and the upper altitude semidiurnal ones. As seen, on the average there are some discrepancies with seasons, in both altitude and overall variability, which may or may not be significant. The seasonal differences are smaller for the low altitude dominant diurnal trace (or layer) for which there is a larger statistical sample. For all practical purposes, the diurnal traces appear to be about the same for all seasons, having relative differences between seasons of $\sim 5$ to $7 \%$. It can be argued that there are no significant differences for the upper daytime and nighttime semidiurnal-like traces as well, although the statistical sample in their cases is possibly insufficient to substantiate this claim. Finally, we conclude that, besides the weak upper altitude diurnal trace that is present at times only during summer, there seems to be no clear systematic trend between seasons that looks significantly different. 


\section{Winter}
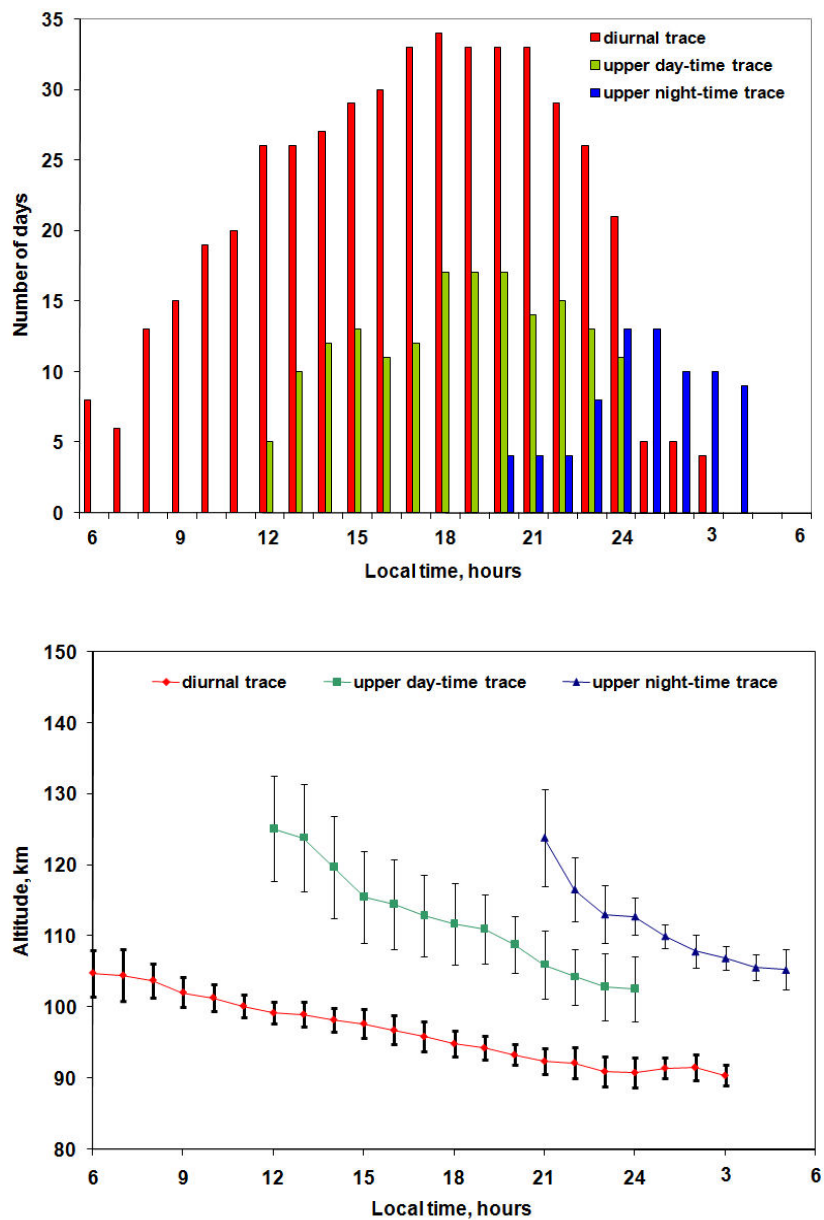

Fig. 4. Statistics of the averaged $E_{S}$ traces as a function of altitude and local time, during a 24-h day starting at 06:00 LT, shown here for winter (December, January, and February). The upper panel presents the occurrence distributions of the three dominant traces shown separately in the lower panel. The error bars represent the mean error. The colors between the two panels are in correspondence.

\section{Tidal wavelength estimates and numerical simulation}

According to the windshear theory (see e.g. Chimonas and Axford, 1968), a layer remains at the shear convergence null only if it forms fast relative to the time needed for the null to propagate downwards (with the phase velocity of the tidal wave) a distance equal to the layer width. For a given tidal mode, the layer can descend with the vertical tidal phase speed at higher E-region altitudes where the ion-neutral collisional control on ion convergence is small. As discussed by Haldoupis et al. (2006), at lower altitudes, the increased number of collisions slows down the vertical descent of the layers because these cannot form fast enough to remain at the convergence null. Thus, they lag behind and descend at in-

\section{Spring}
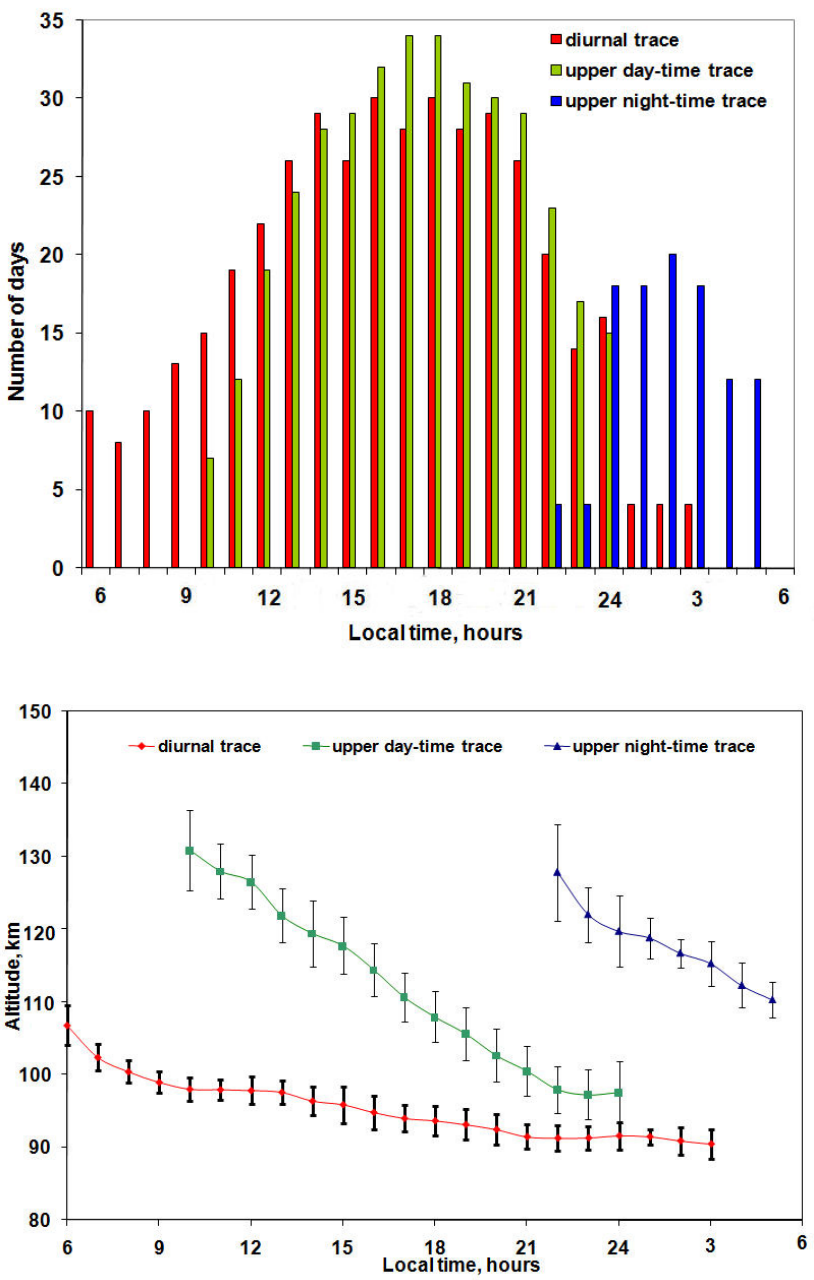

Fig. 5. Same as in Fig. 4 but for spring (March, April, May).

creasingly smaller rates with decreasing altitude as compared to the vertical phase velocity of the tide. This is more likely to occur for the case of the semidiurnal tides than the diurnal ones, since the former phase-propagate downwards faster. As a result of ion-neutral collisional forcing, and in line with theory and observations, a descending $E_{S}$ trace can have a fairly constant slope at upper heights in the altitude versus time frame, which decreases steadily as the layer moves down where ion-neutral collisions become increasingly frequent. Based on this picture, a nearly constant slope at upper heights for the $E_{S}$ trace may provide a good estimate of the downward tidal phase speed.

By considering these facts, $E_{s}$ layer descending speeds can be approximated to the downward phase velocities of the driving tides and thus be used to infer their vertical wavelengths. The estimates obtained this way for the 24-h and 12-h tides, assumed responsible for the observed Arecibo 
Summer
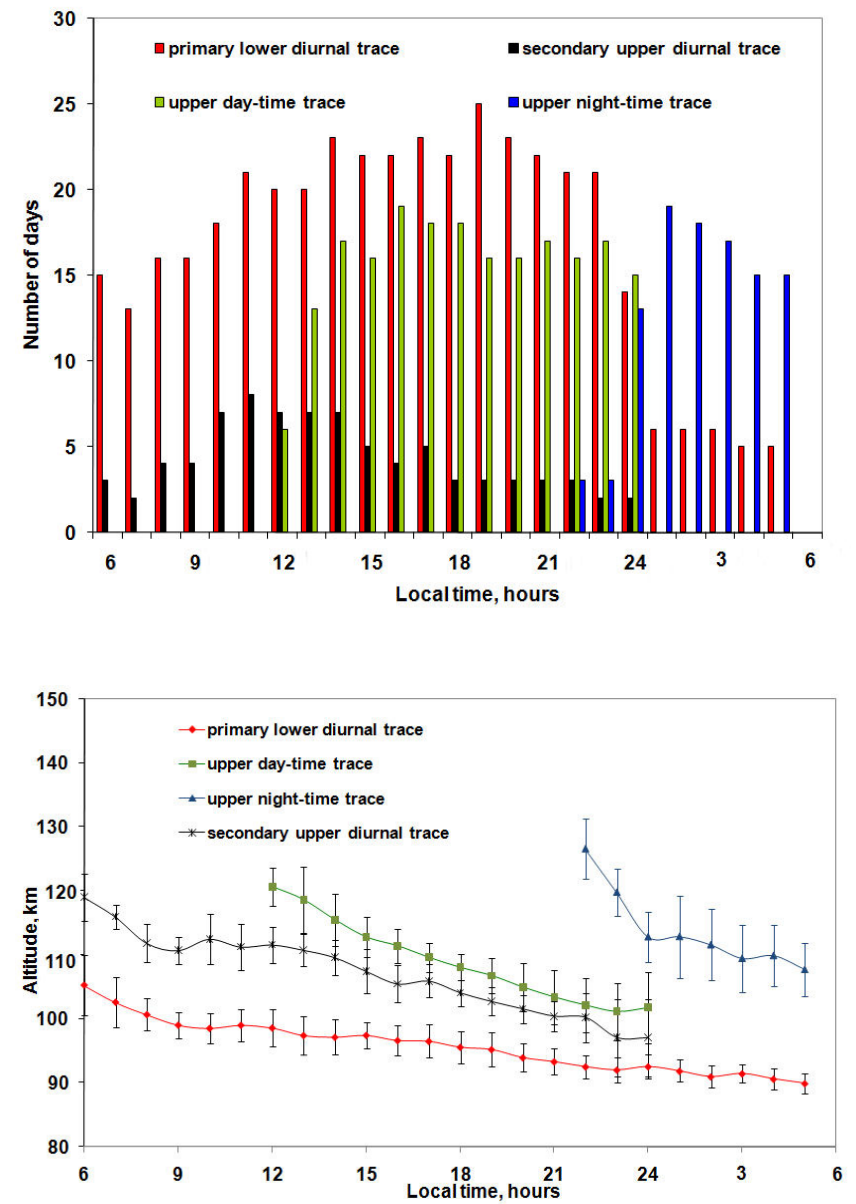

Fig. 6. Same as in Fig. 4 but for summer (June, July, August). See also text for more details.

sporadic E traces, are listed in Table 1. The phase speeds here correspond to the upper heights of the mean traces shown in Figs. 4 to 7, for which the slope computed for consecutive points remains fairly constant (within 10 to $15 \%$ ). We stress, however, that the computed values are likely to be underestimates of the real vertical phase velocities and wavelengths of the tides involved, since ion-neutral collisions are expected to have always some effect for the heights under consideration, that is, below $130 \mathrm{~km}$.

Based on Table 1, the overall mean velocities and wavelengths plus their mean errors inferred for the different $E_{S}$ traces are as follows: a) $1.0 \pm 0.9 \mathrm{~km} / \mathrm{h}$ and $25.5 \pm 2.1 \mathrm{~km}$ for the diurnal trace, b) $3.1 \pm 0.8 \mathrm{~km} / \mathrm{h}$ and $37.1 \pm 4.2 \mathrm{~km}$ for the daytime semidiurnal trace, and c) $3.6 \pm 0.8 \mathrm{~km} / \mathrm{h}$ and $43.5 \pm 1.6 \mathrm{~km}$ for the nighttime semidiurnal trace, respectively. The estimated wavelengths compare well with tidal theory (see e.g. Forbes, 1995) which predicts: 1) a vertical wavelength $\lambda_{z}=27.9 \mathrm{~km}$ for the diurnal tidal mode of $\mathrm{S}(1,1)$, which is dominant in the lower thermosphere below $110 \mathrm{~km}$
Fall
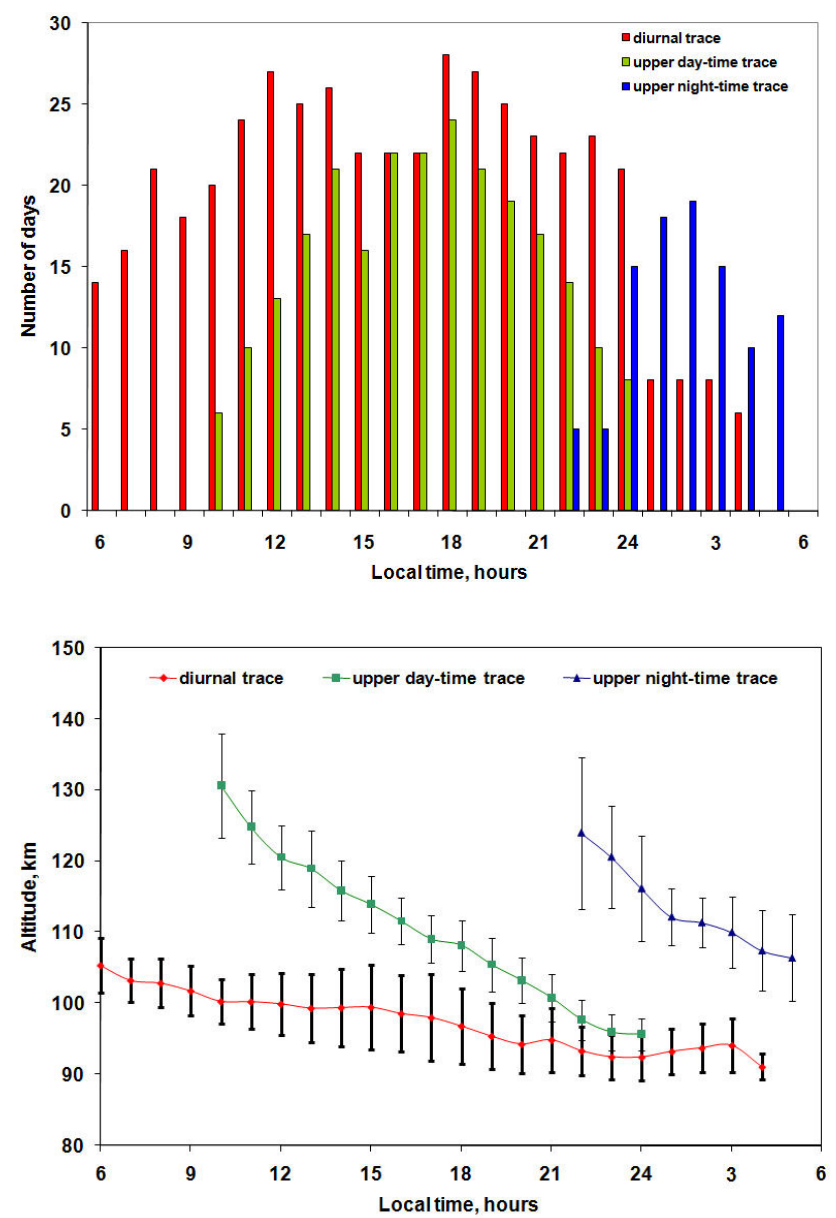

Fig. 7. Same as in Fig. 4 but for fall (September, October, November).

at Arecibo latitudes (see e.g. Harper, 1977), and 2) vertical wavelengths of $33.4 \mathrm{~km}$ and $41.0 \mathrm{~km}$ for the $S(2,6)$ and, $\mathrm{S}(2,5)$ semidiurnal tides, respectively. This suggests that the diurnal $\mathrm{S}(1,1)$ tide is the mode that controls the low altitude diurnal $E_{s}$ trace. On the other hand, the wavelength estimates for the daytime and nighttime upper layers differ somewhat, and thus, can not be ascertained whether the dominant driving semidiurnal tide is the $S(2,6)$ or $S(2,5)$ mode. Since the daytime trace relies on a larger statistical sample, we suggest that the key semidiurnal tide involved is the $S(2,6)$.

Next follow some numerical simulations of the trajectories of the main layers, using the methodology introduced first by Chimonas and Axford (1968) and applied later by Mathews and Bekeny (1978) and more recently by Haldoupis et al. (2006). The simulation was performed separately for the diurnal (lower) and semidiurnal (upper) layers by solving Eq. (1) of Mathews and Bekeny (1978):

$w=\frac{\cos I \sin I}{1+\left(v_{i} / \omega_{i}\right)^{2}} U+\frac{\left(v_{i} / \omega_{i}\right) \cos I}{1+\left(v_{i} / \omega_{i}\right)^{2}} V$, 
Table 1. Estimates of downward propagating phase speeds and wavelengths for the tides in relation with the observed averaged $E_{S}$ traces shown in Figs. 4 to 7 for all seasons.

\begin{tabular}{lllll}
\hline & Winter & Spring & Summer & Fall \\
\hline Dominant diurnal & $u_{d} \sim 1.0 \mathrm{~km} / \mathrm{h}$ & $u_{d} \sim 1.2 \mathrm{~km} / \mathrm{h}$ & $u_{d} \sim 1.1 \mathrm{~km} / \mathrm{h}$ & $u_{d} \sim 0.9 \mathrm{~km} / \mathrm{h}$ \\
& $\lambda \sim 24 \mathrm{~km}$ & $\lambda \sim 28.8 \mathrm{~km}$ & $\lambda \sim 26.4 \mathrm{~km}$ & $\lambda \sim 22.8 \mathrm{~km}$ \\
trace & & & $u_{d} \sim 1.2 \mathrm{~km} / \mathrm{h}$ & \\
Upper diurnal trace & & & $\lambda \sim 28.8 \mathrm{~km}$ & \\
& & & \\
Upper daytime & $u_{d} \sim 3.2 \mathrm{~km} / \mathrm{h}$ & $u_{d} \sim 2.8 \mathrm{~km} / \mathrm{h}$ & $u_{d} \sim 2.6 \mathrm{~km} / \mathrm{h}$ & $u_{d} \sim 3.7 \mathrm{~km} / \mathrm{h}$ \\
Semidiurnal trace & $\lambda \sim 38.3 \mathrm{~km}$ & $\lambda \sim 34.5 \mathrm{~km}$ & $\lambda \sim 31.2 \mathrm{~km}$ & $\lambda \sim 44.4 \mathrm{~km}$ \\
Upper nighttime & $u_{d} \sim 3.7 \mathrm{~km} / \mathrm{h}$ & $u_{d} \sim 3.4 \mathrm{~km} / \mathrm{h}$ & $u_{d} \sim 3.6 \mathrm{~km} / \mathrm{h}$ & $u_{d} \sim 3.8 \mathrm{~km} / \mathrm{h}$ \\
semidiurnal trace & $\lambda \sim 44.4 \mathrm{~km}$ & $\lambda \sim 40.8 \mathrm{~km}$ & $\lambda \sim 43.2 \mathrm{~km}$ & $\lambda \sim 45.5 \mathrm{~km}$ \\
\hline
\end{tabular}

which results from basic windshear theory and gives the vertical ion drift velocity $w$ at steady state. Here, $U$ and $V$ are the geomagnetic southward and eastward components of the neutral wind (representing approximately the meridional and zonal wind components, respectively), $I$ is the magnetic dip angle, and $\left(v_{i} / \omega_{i}\right)=r$ is the ratio of ion-neutral collision frequency to ion gyrofrequency.

Next, Eq. (1) is solved numerically by using a simplified wind system where only a pure tidal zonal wind, either diurnal or semidiurnal, is active. The zonal wind profile is described by the equation:

$$
V=V_{0} \exp \left(\frac{z-z_{0}}{2 H}\right) \cos \left[\frac{2 \pi}{\lambda_{z}}\left(z-z_{0}\right)+\frac{2 \pi}{T}\left(t-t_{0}\right)\right]
$$

where $T$ and $\lambda_{z}$ are the period and vertical wavelength of the tidal wind, $H$ is a representative scale height for the lower thermosphere between 80 and $150 \mathrm{~km}, z_{0}$ is a lower altitude boundary and $t_{0}$ is a fixed tidal wave phase. For more details regarding the use of this model see Mathews and Bekeny (1978) and Haldoupis et al. (2006).

The values employed for the tidal parameters, in order to describe an S(1,1) tidal mode, were: $T=24 \mathrm{~h}, \lambda_{z}=27.9 \mathrm{~km}$, $V_{0}=110 \mathrm{~m} / \mathrm{s}, z_{0}=73 \mathrm{~km}, t_{0}=2 \mathrm{~h}$ and $H=5.5 \mathrm{~km}$. These are similar to those used by Mathews and Bekeny (1978) and Haldoupis et al. (2006) and are consistent with observations of thermospheric tidal winds above Arecibo (Harper, 1977). The shear convergence node was launched at $110 \mathrm{~km}$ at 06:00 LT and the trajectory was followed for $24 \mathrm{~h}$. The results of this simulation are shown in Fig. 9 by the solid curve superimposed over the mean diurnal $E_{S}$ traces for all seasons. As seen, the $\mathrm{S}(1,1)$ trajectory produced by the numerical model follows closely the observed mean diurnal $E_{S}$ traces.

On the other hand, shown also in Fig. 9 are simulated traces for the upper altitude daytime and nighttime layers, attributed mostly to a semidiurnal tidal action. These curves correspond to $\mathrm{S}(2,6)$ with $T=12 \mathrm{~h}, \lambda_{z}=33 \mathrm{~km}, z_{0}=82 \mathrm{~km}$,

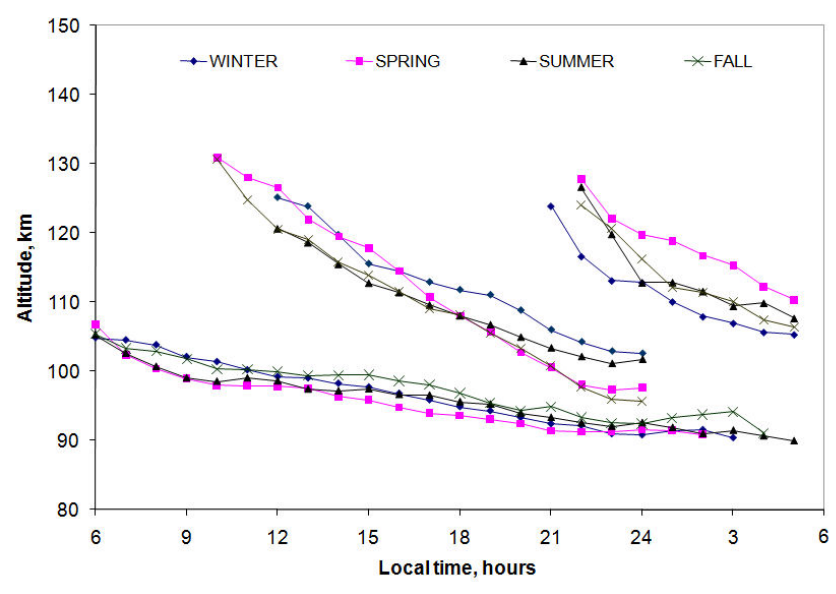

Fig. 8. Superposition of the mean $E_{S}$ traces for the low altitude diurnal trace and upper altitude daytime and nighttime semidiurnal-like traces prevailing in the Arecibo observations for different seasons.

$t_{0}=11 \mathrm{~h}, H=5.5 \mathrm{~km}$ and amplitude $V_{0}=80 \mathrm{~m} / \mathrm{s}$ which is also in line with the findings of Harper (1977). The shear convergence node was launched at $140 \mathrm{~km}$ at 06:00 LT and this pattern was repeated after $12 \mathrm{~h}$. As seen, the simulated trajectories are fairly representative of the observed upper altitude $E_{S}$ traces, although they do not fit the data so well as $\mathrm{S}(1,1)$ does for the diurnal case. This apparently is because the real situation at upper heights is more complicated than it has been assumed. For instance, in our simplified model, we only consider the zonal wind whereas also the meridional wind plays an increasingly important role with increasing height. At about $128 \mathrm{~km}$, near the upper boundary of our present study, both zonal and meridional winds are about equally important in controlling the ion motion. Although the role of meridional wind diminishes exponentially, it may still alter the layer convergence height, especially above $120 \mathrm{~km}$. Another reason could be the fact that 


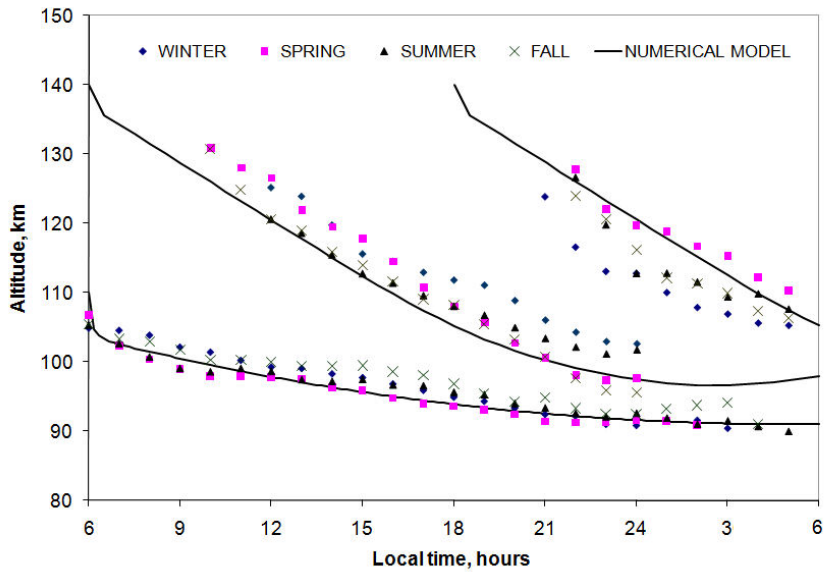

Fig. 9. Windshear numerical simulation results for a diurnal $S(1,1)$ $-\lambda_{z}=27.9 \mathrm{~km}$ (lower solid line trace), and a semidiurnal $\mathrm{S}(2,6)-$ $\lambda_{z}=33 \mathrm{~km}$ (upper solid line traces) zonal tidal wind modes, superimposed over the observed mean $E_{S}$ traces presented for all seasons in Figs. 4 to 7 and Fig. 8. The tidal modes are released near 06:00 LT at $110 \mathrm{~km}$ and $140 \mathrm{~km}$ for the diurnal and semidiurnal tide, respectively. See text for more details.

the upper $E$ region semidiurnal tidal wavelengths increase with altitude, as shown for example by Zhou et al. (2005).

Finally, in the present study we are primarily interested in the layers that showed good continuity. Weak layers before dawn may not be well presented because of the meteoric interference and production of ionization. The work by Zhou et al. (2005) does not impose any continuity requirement on the layers. Consequently, they show more layers especially before the dawn hours. Their Fig. 3 indicates a high probability of layer occurrence slightly below $105 \mathrm{~km}$ during 02:00-06:00 LT. The altitude and lack of any obvious phase velocity of this layer match well with the model result of the assumed semidiurnal $\mathrm{S}(2,6)$ tide shown in Fig. 9. Overall, it thus seems that the simplified wind model used here for simulation supports a consistent physical picture in relation with the formation and descent of sporadic $\mathrm{E}$ at low latitudes.

\section{Summary and concluding comments}

The present analysis allowed for the first time to obtain seasonal statistics of sporadic E layer vertical motion and altitudinal variability as a function of local time at Arecibo (Geog. Lat. $18^{\circ} \mathrm{N}$; magnetic dip $\sim 50^{\circ}$ ). The general picture, which is similar for all seasons, is dominated by a diurnal layer at lower altitudes below $110 \mathrm{~km}$ and a set of two layers at higher altitudes, a daytime and a nighttime one, that appear to be controlled mainly by semidiurnal tides. Although there are some differences in the descent speed, layer multiplicity and frequency of occurrence, the statistical analysis shows no dramatic changes with season. Regardless of their number density, this is indicative of how regular these layers appear to be all the time, which may not be surprising, since Arecibo is a low latitude location characterized in general by small seasonal change. We should stress that, although it remains similar, the picture becomes more complex and dynamic during summer, when sporadic $E$ is known to reach a conspicuous maximum in occurrence and strength (see e.g. recent paper by Haldoupis et al., 2007). In this respect however, the summer differences seen here relative to the rest of the seasons are not drastic and thus, we conclude that they cannot play the decisive role behind the pronounced $E_{s}$ summer maximum.

The present results show that on the average, the diurnal tide is the key agent responsible for the formation of strong sporadic $\mathrm{E}$ at lower altitudes for all seasons. In their diurnal course, the layers form, presumably at tidal convergence nulls, near $107 \mathrm{~km}$ at $\sim 06: 00 \mathrm{LT}$ and move down to altitudes near or below $90 \mathrm{~km}$ in about $24 \mathrm{~h}$. This can be understood by considering the amplitude, phase and downward propagation speed of the $\mathrm{S}(1,1)$ diurnal tide having a vertical wavelength of $\sim 25 \mathrm{~km}$, as predicted by theory. In addition, a weaker diurnal trace is also seen at higher altitudes only during summer, starting at $\sim 120 \mathrm{~km}$ near 06:00 LT and moving downwards at about the same speed as the main $E_{s}$ trace at lower heights. This seemingly implies that the diurnal $S(1,1)$ tide starts at higher altitudes in summer than in other seasons.

The effects of the semidiurnal tides on $E_{s}$ variability and descent appear on the average similar for all seasons but their role on $E_{S}$ is less conclusive. The upper altitude daytime and nighttime layers have somewhat different descent speeds, duration and frequency of occurrence. Provided that these differences are statistically significant, they imply at first that a different semidiurnal mode acts on $E_{s}$ formation during day (of shorter vertical wavelength close to that of $S(2,6)$ than at night (longer vertical wavelength close to that of $S(2,5)$ ). This inference however is difficult to be justified, thus there may be another reason in place. For instance, it could be that the daytime tidal dynamics become more complicated under the forcing of photochemical heating. Also, one may postulate the presence during the day or night of additional tidal components which add up to affect the daytime and nighttime semidiurnal effects on ion convergence differently. For example, it is likely that weaker quarterdiurnal or terdiurnal tidal modes are also present at times, as shown for example by Morton et al. (1993) and Haldoupis and Pancheva (2006), which contaminate the semidiurnal picture. As for the difference in occurrence between the daytime and nighttime upper altitude layers, the possibility exists that the daytime layer sweeps down the metallic ion population, which is increased during daytime by photoionization, so that the medium is relatively depleted during the night hence, making it difficult for the nighttime layer to form. The observed differences between the daytime and nighttime upper layers revealed in the present study are interesting but not well understood and thus, deserve further consideration and need a larger statistical sample to be analyzed. 
The present results agree in general with single Arecibo ISR run studies of descending tidal ion layers (see review paper by Mathews, 1998, and more references therein). As for the higher latitude (typical mid-latitude) sporadic E tidal variability, there are very few studies of the type presented here. The most recent one is by Haldoupis et al. (2006), where ionosonde observations taken at the island of Milos (Geog. Lat. $\sim 36^{\circ} \mathrm{N}$; magnetic dip $\sim 52^{\circ}$ ) are used to obtain during summer time-averaged HTI plots showing a pronounced periodicity in layer descent and occurrence. This is dominated by a daytime layer starting at $120 \mathrm{~km}$ near 06:00 LT and moving downwards (with speeds of $\sim 1.0 \mathrm{~km} / \mathrm{h}$ ) to altitudes below $100 \mathrm{~km}$ by 18:00 LT, whereas a nighttime layer appeared at about midday above $130 \mathrm{~km}$ which moves also downwards but at higher descent rates $(\sim 2.2 \mathrm{~km} / \mathrm{h})$. A comparison of these results with the present findings shows a good deal of similarity, although differences do also exist, mostly in relation with the altitude of the diurnal tidal trace of sporadic $\mathrm{E}$, which may be due to latitudinal differences in tidal variability. There are no continuous ionosonde records during the other seasons of the year to tell us what is happening because the layers are weaker and thus often cannot be detected by ionosondes.

The present Arecibo statistical results on sporadic E formation and descent for all seasons represent the first evidence of this type. They can be useful in the study of tides in the lower thermosphere between 90 and $130 \mathrm{~km}$ at low latitudes but well outside the equatorial anomaly. Recent studies (D. Pancheva, private communication) based on SABER Satellite temperature data in the altitude range from 100 to $120 \mathrm{~km}$, show that for latitudes near $\left.20^{\circ}: 1\right)$ the migrating semidiurnal tide with vertical wavelengths between 36 and $40 \mathrm{~km}$ is fairly dominant, and 2) the diurnal tide is also strong having a vertical wavelength near $20 \mathrm{~km}$. These results appear to be in good agreement with those inferred from the present study.

Acknowledgements. The Arecibo Observatory is operated by Cornell University under a cooperative agreement with National Science Foundation.

Topical Editor K. Kauristie thanks two anonymous referees for their help in evaluating this paper.

\section{References}

Bishop, R. L., Earle, G. D., Gonzalez, S. A., Sulzer, M. P., and Collins, S. C.: Inferred vertical ion velocities associated with intermediate layers, J. Atmos. Solar-Terr. Phys., 64, 1471-1477, 2002.

Bishop, R. L. and Earle, G. D.: Metallic ion transport associated with midlatitude intermediate layer development, J. Geophys. Res., 108(A1), 1019, doi:10.1029/2002JA009411, 2003.
Carter, L. N. and Forbes, J. M.: Global transport and localized layering of metallic ions in the upper atmospherer, Ann. Geophys., 17, 190-209, 1999, http://www.ann-geophys.net/17/190/1999/.

Chapman, S. and Lindzen, R. S.: Atmospheric Tides, D. Reidel, Hingham, MA, 1970.

Chimonas, G. and Axford, W. I.: Vertical movement of temperate zone sporadic E layer, J. Geophys. Res., 73, 111-117, 1968.

Earle, G. D., Bishop, R. L., Collins, S. C., Gonzalez, S. A., and Sulzer, M. P.: Descending layer variability over Arecibo, J. Geophys. Res., 105A, 24951-24961, 2000.

Fedorov, S.: GetData Graph Digitizer, available at www. getdata-graph-digitizer.com, 2008.

Forbes, J.: Tidal and Planetary Waves, in: The Upper Mesosphere and Lower Thermosphere: A Review of Experiment and Theory, Geophysical Monograph, 87, AGU, 67-87, 1995.

Haldoupis, C., Meek, C., Christakis, N., Pancheva, D., and Bourdillon, A.: Ionogram height-time intensity observations of descending sporadic E layers at mid-latitude, J. Atmos. Solar-Terr. Phys., 68, 539, doi:10.1016/j.jastp.2005.03.020, 2006.

Haldoupis C. and Pancheva, D.: Terdiurnal tidelike variability in sporadic E layers, J. Geophys, Res., 111, A07303, doi:10.1029/2005JA011522, 2006.

Haldoupis, C., Pancheva, D., Singer, W., Meek, C., and MacDougall, J.: An explanation for the seasonal dependence of midlatitude sporadic E layers, J. Geophys. Res., 112, A06315, doi:10.1029/2007JA012322, 2007.

Harper, R. M.: Tidal winds in the 100- to 200-km region at Arecibo, J. Geophys. Res., 82, 3243-3250, 1977.

Mathews, J. D.: Sporadic E: current views and recent progress, J. Atmos Solar-Terr. Phys., 60, 413-435, 1998.

Mathews, J. D. and Bekeny, F. S.: Upper atmospheric tides and the vertical motion of ionospheric layers at Arecibo, J. Geophys. Res., 84, 2743-2750, 1979.

Morton, Y. T., Mathews, J. D., and Zhou, Q.: Further evidence for a 6-h tide above Arecibo, J. Atmos. Terr. Phys., 55, 459-465, 1993.

Pancheva, D., Haldoupis, C., Meek, C. E., Manson, A. H., and Mitchell, N. J.: Evidence of a role for modulated atmospheric tides in the dependence of sporadic E layers on planetary waves, J. Geophys. Res., 108(A5), 1176, doi:10.1029/2002JA009788, 2003.

Whitehead, J. D.: Recent work on midlatitude and equatorial sporadic E, J. Atmos. Terr. Phys., 51, 401-424, 1989.

Zhou, Q.: Two-day oscillation of electron concentration in the lower ionosphere, J. Atmos. Solar-Terr. Phys., 60, 1669-1677, 1998.

Zhou, Q., Friedman, J., Raizada, S., Tepley, C., and Morton, Y. T.: Morphology of nighttime ion, potassium and sodium layers in the meteor zone above Arecibo, J. Atmos. Solar-Terr. Phys., 67, 1245, doi:10.1016/j.jastp.2005.06.013, 2005.

Zhou, Q., Raizada, S., Tepley, C., and Plane, J.: Seasonal and diurnal variation of electron and iron densities at the meteor heights above Arecibo, J. Atmos. Solar-Terr. Phys., 70, 49, doi:10.1016/j.jastp.2007.09.012, 2008. 